\title{
ATTITUDE IN ABSTRACTS: \\ STANCE EXPRESSION IN TRANSLATION PRACTICE REPORTS AND INTERPRETATION PRACTICE REPORTS BY CHINESE STUDENTS
}

\author{
Fengling Wang and Issra Pramoolsook
}

\begin{abstract}
Given the importance of stance expression in the writing of abstracts, this study adopted a corpus-based comparative approach to investigate the stance expression in abstracts of the Translation Practice Report (TPR) and the Interpretation Practice Report (IPR), which are two newly emerging reporting genres in Master of Translation and Interpretation (MTI) in China. Based on a set of corpora composed with 30 TPR abstracts (8,738 tokens) and 30 IPR abstracts $(8,699$ tokens) collected from 30 universities located in 16 provinces in China, the stance expression was examined in terms of hedges, boosters, attitude markers, and self-mention by employing the stance framework in Hyland's (2005) interactional model. The findings revealed a genre-specific convention in utilizing the four categories of stance in both the TPR abstracts and the IPR abstracts, which is different from that in the abstracts of the empirical studies. The analysis also found discipline-specific variations of stance expression between the two corpora due to different disciplinary conventions and practice of the two subdisciplines. Then, the interviews with the insider informants were conducted to clarify and to enrich the research findings. The results in the study may be taken as a useful reference to expressing attitude in writing the abstracts in the MTI field of China, and possibly in other fields.
\end{abstract}

\section{Keywords}

stance expression, Chinese English thesis abstracts, reporting genre, L2 Chinese learner discourse, genre-specific convention, disciplinary variation

\section{Introduction}

It is well acknowledged that academic writing is no longer regarded as a faceless, objective and impersonal writing behavior. Instead, it is taken as writers' endeavor to construct their personas through persuading their readers and initiating some interaction with readers (Hyland 1999, 2005). Hence, "the ways that writers and speakers express their opinions have long been recognized as an important feature of language" (Hyland 2005: 174). This important language feature is closely related to stance, which refers to "the ways [that] writers present themselves and convey their judgments, opinions and commitments" (Hyland 2005: 176). 
In the latest decades, adopting stance framework in Hyland's (2005) interactional model, a considerable amount of studies on stance expression have been conducted in various genre-specific contexts, covering research articles (RAs) (Hyland 1999, 2005, Auría 2008, McGrath \& Kuteeva 2012, Taki \& Jafarpour 2012, Adams \& Quintana-Toledo 2013, Hyland \& Jiang 2016, Kafes 2018, Poole et al. 2019), M.A. theses and Ph.D. dissertation (Xu 2015), reports (Crosthwaite et al. 2017, Fuoli 2017), students' essays (Aull \& Lancaster 2014, Çandarlı et al. 2015, Jiang 2015, Aull et al. 2017), students' course work (Lancaster 2016). Furthermore, among those studies, the stance expression in the section in RAs or Ph.D. dissertations has been examined, including Introduction (Auría 2008), Discussion (Cheng \& Unsworth 2016), Conclusion (Kafes 2018), Introduction and Conclusion (Adams \& Quintana-Toledo 2013, Loi et al. 2016) in RAs, Acknowledgement (Chan 2015) in Ph.D. dissertation, even Abstract in RAs (Hyland \& Tse 2005, Gillaerts \& Van de Velde 2010, Hu \& Cao 2011) and Abstract in Engineering Ph.D. thesis (Ahmad \& Mehrjooseresht 2012). In addition, several studies have been carried out to reveal the variations of the stance expression across different disciplines (Hyland 1999, 2005, Taki \& Jafarpour 2012, Çandarlı et al. 2015, Jiang 2015). However, in spite of many gains in a broad range of genres and sections, little attention has been given to the abstracts in the Translation Practice Report (TPR) and in the Interpretation Practice Report (IPR), which are two newly emerging reporting genres for qualifying Chinese students for master's degrees in the field of translation and interpretation. Besides, few attempts have been made to explore the disciplinary variations of stance expression between the abstracts in the two subdisciplines.

Therefore, this paper, drawing on the stance framework in Hyland's (2005) interactional model, aims to examine how Chinese students operate stance expression to express their epistemic assessment and attitude, to present themselves, and to construct interaction with the putative readers in the section of abstracts in the two genres that are crucial in the field of translation and interpretation in China. It also intends to explore the possible disciplinary variations on Chinese students' knowledge construction by utilizing stance devices between the two closely related subdisciplines. In line with those purposes above, two specific research questions are generated, as follows:

1. What are the features of stance expression, in terms of the percentage distribution of hedges, boosters, attitude markers, and self-mention, in the TPR abstracts and the IPR abstracts?

2. How are the features of stance expression in the TPR abstracts similar to or different from those in the IPR abstracts? 
By doing so, it is hoped that the results in the study may be taken as a useful reference to understand stance expression in the TPR abstracts and the IPR abstracts. Also, it is believed that the results will help raise the stance expression awareness of the students and teachers in the MTI field in their writing and teaching. Besides, it is hoped that the stance features found in the study will benefit academic writers in other fields as well.

\section{The TPR abstracts and the IPR abstracts}

In this paper, the Translation Practice Report (TPR) and the Interpretation Practice Report (IPR) are two sub-types of degree theses written in English by Chinese students undertaking the program of Master of Translation and Interpretation (MTI). The MTI program, as a newly emerging professional master's degree, was initiated in 2007 and has gained great popularity in China to meet the social needs for professional translators and interpreters. Driven by the social expectations, the syllabus, curriculum and degree theses in the MTI program are practice-emphasized rather than research-oriented. In this regard, the TPR and the IPR were designated as degree theses to prove what professional level the translation students and the interpretation students have reached after their three years' theoretical learning and translation/interpretation practice. As the non-empirical research genres, both the TPR and the IPR are equal to other graduate research genres (e.g. M.A. theses) in Chinese degree community in terms of their academic status. Following Swales' (1990) view on genre, both the TPR and the IPR have their communicative purposes, audiences, and structural patterns. Specifically, the communicative purposes of the TPR and the IPR are mainly to give a report on a translation/interpretation practice task, aiming to describe its background, purposes, procedures, problems, techniques, and implications (Huang 2012). At the same time, as the master's theses, they aim to convince the graduate committee of the report writer's qualification for a master's degree. In line with the communicative purposes, the audiences of the two genres include not only the potential student readers in the MI field but also graduate committee members who examine the theses. Guided by the communicative purposes, the structural contents of the TPR and the IPR constitute English Abstract, Chinese Abstract, Main body of the thesis (report), References, and Appendices.

As one indispensable constituent, situated at the beginning of the theses, the English abstract in the TPR or in the IPR is the first thing that the examiners read to evaluate the contribution of a practice report to the translation and the interpretation field. It is thus instrumental in constructing an impression of a student who has the legitimate qualification for his or her master's degree. 
Especially, an abstract is an instructive summary of a much longer work, which is not only informative but also advertising and promoting its accompanying work (Hyland 2000). That is to say, the TPR abstracts and the IPR abstracts not only inform the potential readers and committee examiners of the contents in the translation/interpretation practice reports, but also persuade them to read the whole work by effectively manipulating rhetorical and linguistic choices which are closely related to stance expression. However, in the MTI field, although some writing lectures such as Academic Writing and MTI Theses Writing are provided for the students based on the course syllabus, one area that is always neglected in those writing courses is the stance expression. Besides, though students are usually guided to know what constituents should be composed into the abstracts of the TPR and the IPR via the writing manuals, the lack of explicit instruction of stance expression in the TPR abstracts and the IPR abstracts is also a case.

Therefore, it seems worth examining the stance features in the abstracts of these two specific genres to offer the corresponding pedagogies. In addition, considering that the stance devices are usually constrained by the disciplinary conventions, it is supposed to be pedagogically meaningful to investigate the potential disciplinary variations between the two closely related subdisciplines by employing an appropriate theoretical framework on stance.

\section{Theoretical framework for the study}

Stance is an elusive concept. The interpretations of stance in the last three decades had an undeniable relation to the umbrella terms of evaluation (Thomson \& Hunston 2000), appraisal (Martin \& White 2005), evidentiality (Chafe \& Nichols 1986), metadiscourse (Vande Kopple 1985, Hyland \& Tse 2004, Hyland 2005), and stance (Hyland 2005, Biber 2006). In spite of various approaches to stance, they focus on exploring the ways in which writers and speakers project their epistemic judgments, affective attitudes, and engagement in what they produce. Especially, since academic writing is considered to be persuasive rather than merely objective and faceless (Hyland 1999, Hyland \& Tse 2004), stance is understood as various linguistic devices to enhance persuasiveness and impersonal objectivity through constructing the interaction between writers and readers (Hyland 1999, 2005). In this regard, the interaction in academic writing is modelled by Hyland (2005) into two dimensions: stance and engagement. Here stance refers to the projection of writers and their propositions to both content and readers, and engagement describes how writers address their readers and involve them into a dialogue. 
In this paper, in line with Hyland's (2005) interactional perspective, stance expression is taken as the projection of the writers in the text and the interaction constructed between writers and the readers in terms of the writer-oriented linguistic features. Consequently, stance consists of four categories of linguistic features: (1) hedges (e.g. possible, may), which withhold complete commitment to a proposition; (2) boosters (e.g. obvious, must), which express writer's certainty with the topic and their solidarity with readers; (3) attitude markers (e.g. prefer, important), which indicate writer's attitude to propositions, expressing affective feelings like agreement, importance, and so on; and (4) self-mention (e.g. I), which is concerned with presence of writers through the use of first person pronouns and possessive adjectives.

In the field of the MTI in China, students are found to make efforts in linguistic options to persuade examiners to believe the 'trueness' or the reliability of what they have reported in writing the TPR abstracts and the IPR abstracts. That is to say, the students' epistemic evaluation, attitudes, and presence are highly involved in the abstracts to prove the value of their reports. Those linguistic options are closely related to the functions of the stance defined by Hyland (2005) in terms of boosters, hedges, attitude markers, and self-mention. To put it succinctly, students express the extent of certainty they hold to the translation/interpretation issues in the abstracts through boosters and hedges, display their attitudes and feelings they have in the abstracts via attitude markers, and show their presence and involvement in the abstracts through the self-mention. Therefore, it is apparent that the construction of the students' attitudinal meanings which are complemented by explicit assessment, attitude, presence, and engagement in the TPR abstracts and the IPR abstracts in terms of the four stance categories is significant in promoting the value of the practice reports and in convincing the examiners that the contribution of the practice reports is worth a master's degree.

Besides, considering that "stance options are constrained by the rhetorical expectations of the discourse" (Crosthwaite et al. 2017: 109), the notions of the four categories of stance in the study were modified in line with the communicative purposes in the TPR abstracts and the IPR abstracts. The modified function of each category of stance and the specific example in the contexts of the TPR abstracts and the IPR abstracts are offered in Table 1. Correspondingly, Hyland's (2005) stance list was modified by the researchers through adding the TPR and the IPR discipline-specified stance items (e.g. translator and interpreter for self-mention) into the four categories through a scrutiny over the two corpora (see Appendix A). By taking the modified stance framework as an instrumental framework, it is hoped to concretize the ways that translation students' and interpretation students' stance construction in the TPR abstracts 
and the IPR abstracts and to virtualize the disciplinary options available in the two subdisciplines.

\begin{tabular}{|l|l|l|}
\hline \multicolumn{4}{|c|}{ Stance expression in the TPR abstracts and the IPR abstracts } \\
\hline Category & \multicolumn{1}{|c|}{ Function } & \multicolumn{1}{c|}{ Examples } \\
\hline Hedges & $\begin{array}{l}\text { The reporter's (translator's/interpreter's) } \\
\text { decision to withhold complete } \\
\text { commitment to a proposition in a TPR } \\
\text { abstract or an IPR abstract }\end{array}$ & $\begin{array}{l}\text { e.g. Generally, almost all translation } \\
\text { works should abide by functional } \\
\text { equivalence. }\end{array}$ \\
\hline Boosters & $\begin{array}{l}\text { The reporter's (translator's/interpreter's) } \\
\text { expression of the certainty about the } \\
\text { veracity of the translation/interpretation } \\
\text { practice task and mark the reliability of } \\
\text { translation/interpretation process and his } \\
\text { or her solidarity with the audience }\end{array}$ & $\begin{array}{l}\text { e.g. In order to translate biographical } \\
\text { articles skillfully and properly, } \\
\text { translators must } \text { know the features of } \\
\text { such articles. }\end{array}$ \\
\hline $\begin{array}{l}\text { Attitude } \\
\text { markers }\end{array}$ & $\begin{array}{l}\text { The reporter's (translator's/interpreter's) } \\
\text { attitude to issues involved in a TPR } \\
\text { abstract or an IPR abstract }\end{array}$ & $\begin{array}{l}\text { e.g. This kind of translation mode is } \\
\text { easy to operate, what is more important, } \\
\text { it provides high efficiency. }\end{array}$ \\
\hline Self-mention & $\begin{array}{l}\text { The presence of the reporter (translator/ } \\
\text { interpreter) in a TPR abstract or an IPR } \\
\text { abstract through the mention of the } \\
\text { reporter (e.g. translator/interpreter), } \\
\text { the use of first-person pronouns and } \\
\text { possessive adjectives }\end{array}$ & $\begin{array}{l}\text { e.g. The translator hopes that the thesis } \\
\text { can become guidance and reference } \\
\text { for the translator's further translation } \\
\text { study. }\end{array}$ \\
\hline
\end{tabular}

Table 1: Stance expression in the TPR abstracts and the IPR abstracts (modified from Hyland 2005)

\section{Methodology}

\subsection{Corpora}

"A corpus-based approach requires analysis of a well-designed 'representative' collection of texts of a particular genre" (Biber et al. 2007: 36). In order to achieve good representativeness of the corpus, the researchers tried to collect the TPR abstracts and the IPR abstracts written in English from universities with different academic levels and in different regions of China. Due to the inaccessibility to hard copies of theses from universities located in various regions of China, Chinese Masters' Theses Full-text Database (CMFD) in China National Knowledge Infrastructure (CNKI), which is regarded as one of reliable online databases offering the full text of master's theses in China, was chosen as the source to collect the TPR abstracts and the IPR abstracts. 
A multi-phased sampling procedure was adopted to compile the TPR abstracts corpus and the IPR abstracts corpus. As part of a larger and ongoing study whose corpus size was decided to hold 30 TPR texts and 30 IPR texts, the size of the corpus in this paper correspondingly contains 30 TPR abstracts and 30 IPR abstracts. To achieve the size, the following steps were conducted. Firstly, the researchers identified the total number of universities that offer the MTI program in China according to the official list issued by the China National Committee for Translation \& Interpreting Education (CNCTIE), and there were 159 universities at the point when researchers began building the corpora in the first half of 2017. Secondly, these 159 universities were classified into four categories of institutions according to the educational orientation, educational level, and academic status, which led to four sampling strata, which are Foreign Language Institutions (abbreviated as FLI, referring to the foreign languages education-oriented universities), 985 Project Institutions (abbreviated as 985PI, referring to the world top universities), 211 Project Institutions (abbreviated as 211PI, referring to the nationally known universities), and Common Institutions (abbreviated as CI, referring to the local universities). Thirdly, by employing the proportional stratified sampling strategies, the number of universities in each sampling strata from which the corresponding number of abstracts should be collected was calculated based on the proportion that was obtained on the number of universities of each type of institution to the total number of universities offering the MTI program in China. As shown in Figure 1, because the number of universities that offer the MTI program in the FLI, the 985PI, the 211PI, and the CI were ten (6\%), $32(20 \%), 49(31 \%)$ and $68(43 \%)$, respectively, two universities representing six per cent of the corpus size from the FLI stratum, six representing 20 per cent from the 985PI stratum, nine representing 31 per cent from the 211PI stratum, and 13 representing 43 per cent from the CI stratum were sampled accordingly. Lastly, the corresponding number of English abstracts was extracted from the TPR texts and the IPR texts which were randomly sampled from the universities in each stratum via the online database of CMFD in CNKI. 

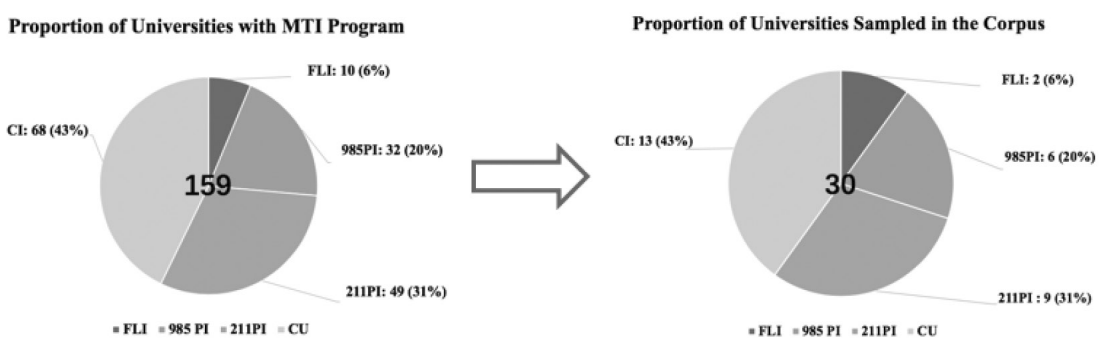

Figure 1: The proportional stratified sampling of the TPR abstracts and the IPR abstracts

Following the steps above, a set of corpora with a good representativeness was completed. The detailed information is demonstrated in Table 2 below.

\begin{tabular}{|l|l|l|l|l|l|l|l|l|}
\hline \multirow{2}{*}{ Corpus } & \multirow{2}{*}{$\begin{array}{l}\text { Number } \\
\text { of } \\
\text { abstracts }\end{array}$} & \multicolumn{2}{|l|}{ Number of abstracts in each stratum } & $\begin{array}{l}\text { Number of } \\
\text { universities }\end{array}$ & $\begin{array}{l}\text { Number } \\
\text { of } \\
\text { provinces }\end{array}$ & Tokens \\
\hline TPR-A & 30 & 2 & 6 & 9 & 13 & 30 & 16 & 8,738 \\
\hline IPR-A & 30 & 2 & 6 & 9 & 13 & 30 & 16 & 8,699 \\
\hline
\end{tabular}

Table 2: Summary of the TPR abstracts corpus and the IPR abstracts corpus

\subsection{Annotation}

For the annotation of stance expression, 30 TPR abstracts and 30 IPR abstracts in the TPR-A and the IPR-A were respectively converted into TEXT files. Then, the concordance program AntConc (Anthony 2011) was employed to annotate the possible stance expression based on the modified Hyland's (2005) stance list which consists of the four categories of stance: namely, hedges, boosters, attitude markers, and self-mention. Next, to obtain the reliability of the concordance, each stance item identified underwent a manual double-check in the concordance line by a researcher "to avoid making superficial assumptions of form-function correspondence and to exclude extraneous examples" (Hyland 2017: 19). Besides, a Ph.D. candidate with an applied linguistic background was invited to conduct the annotation reliability check with a researcher of this study. The inter-coder agreement was reported with 95.8 per cent for TPR-A and 96.5 per cent for IPR-A, respectively. Lastly, the frequency of each category of stance was calculated and normalized per 1,000 words for further analysis. 


\subsection{Analysis procedures}

For analysis procedures, three steps were included. Firstly, the raw number of each category of stance and its percentage distribution, in terms of hedges, boosters, attitude markers, and self-mention, in the TPR-A and the IPR-A were examined, which intends to demonstrate the features of stance expression in the TPR abstracts and the IPR abstracts. Secondly, the frequency of each category of stance expression was compared between the TPR-A and the IPR-A, which aims to reveal the variations in stance making between the two closely related subdisciplines in the field of translation and interpretation. Lastly, following Hyland's (2005) approach, interviews with the insider informants were conducted in a semi-structured format (see Appendix B). That is, the open-ended questions were employed to prompt interviewees' insider community understandings of some particular results found in the above two steps. For the interviewees, four students (two translation students and two interpretation students) and two supervisors in the field of the MTI in China were invited to provide their perspective on some particular results in the study. Chinese was adopted to be the interview language considering the accuracy and efficiency in eliciting the tacit understanding of stance expression in the TPR abstracts and the IPR abstracts. Then, the information from the interviews was extracted and translated to strengthen the research findings in this study.

\section{Results and discussion}

\subsection{The features of stance expression in the TPR abstracts and in the IPR abstracts}

Table 3 below offers the descriptive results on the raw number and its corresponding percentage of stance expression, in terms of hedges, boosters, attitude markers, and self-mention, annotated in the TPR-A and in the IPR-A. As we can see, self-mention had the highest percentage among the four categories of stance in both the TPR-A and the IPR-A, accounting for 42.1 per cent and 57.9 per cent, respectively. Hedges covered the second biggest proportion of total stance items in both corpora, comprising 31.9 per cent and 26 per cent, respectively. Attitude markers displayed a higher percentage in both corpora than boosters, with 19.4 per cent in the TPR-A and 9.9 per cent in the IPR-A. Boosters occupied the least proportion in both of the corpora, comprising 6.5 per cent and 6.2 per cent, respectively. 
ATtitude in ABSTRACTS: StANCE EXPRESSION IN TRANSLATION PRACTICE REPORTS AND INTERPRETATION PRACTICE REPORTS BY CHINESE STUDENTS

\begin{tabular}{|l|c|c|c|c|c|c|c|}
\hline Corpus & \multirow{N}{*}{ Tokens } & \multicolumn{5}{|c|}{ Annotated token } & \multirow{2}{*}{ Total } \\
\cline { 4 - 7 } & & & Hedges & Boosters & Attitude markers & Self-mention & \\
\hline TPR-A & \multirow{2}{*}{30} & 8,738 & 94 & 19 & 58 & 125 & 296 \\
& & & $31.9 \%$ & $6.5 \%$ & $19.4 \%$ & $42.1 \%$ & $100 \%$ \\
\hline IPR-A & \multirow{2}{*}{30} & 8,699 & 73 & 17 & 28 & 163 & 281 \\
& & & $26.0 \%$ & $6.2 \%$ & $9.9 \%$ & $57.9 \%$ & $100 \%$ \\
\hline
\end{tabular}

Table 3: Stance expression annotated in the TPR-A and the IPR-A

From the results above, it is found that the percentage distribution of the four categories of stance in both the TPR abstracts and the IPR abstracts demonstrates a genre-specific feature, which is constrained by the convention of the reporting genre. Since a report is to recount the events or the tasks in a concise and factual way (Bowden 2004), it is characterized by the presence of the reporter and the language that is descriptive and informative. Affected by this genre feature, it can be seen that self-mention had the highest distribution percentage, followed by hedges, attitude markers, and boosters in both corpora. This percentage distribution varied from that in abstracts of other genres, such as RA abstracts on empirical studies in which hedges/boosters usually had the highest percentage. To some extent, this finding is in line with the results found by Gillaerts and Van de Velde (2010) that different genres would lead to the different distribution of hedges, boosters, and attitude markers. In the following sections, this genre-specific feature will be discussed in terms of each category of stance.

Concerning self-mention, it showed the highest percentage in both the TPR-A and the IPR-A, accounting for 42.1 per cent and 57.9 per cent, respectively. The reason for the highest percentage of self-mention could be possibly attributed to the generic nature of the TPR and the IPR that is a report on the non-empirical study in which writers tend to be the acting agents and be more visible in their writing (Hu \& Cao 2011: 2797). With a close look on the data from the TPR-A and the IPR-A, it was found that the translator and the interpreter was respectively preferred by the translation students and the interpretation students to show the presence of the writer. Excerpts from the corpora are provided below:

(1) After finishing the translation task, the translator has gained a deeper understanding of the explanatory power of Relevance Theory and how to handle religious texts translation. (TPR-A-29)

(2) The interpreter wishes this report could be helpful for interpreters who need to finish similar tasks in the future. (IPR-A-7) 
As can be seen from above, self-mention was utilized by both the translation students and the interpretation students to summarize the reports in the TPR abstracts and the IPR abstracts. Doing so, it can enhance the trustworthy of the abstracts by mentioning explicitly the 'actors' of the translation or interpretation practice. This point was made in the interview by both translation and interpretation interviewees by stating that:

We have to very often use 'the translator' and 'the interpreter' when writing the abstracts.

Therefore, the abstract of both TPR and IPR is a piece of concise source information for a type of reporting genre with the communicative purposes of describing the translation/interpretation practice rather than for RAs on empirical studies with the communicative function of claiming propositions through reporting the research process. It is no surprise that self-mention covered the highest percentage among the four categories of stance.

With regard to hedges, about one third of stance expressions annotated in both corpora were hedges $(31.9 \%$ and $26.0 \%$ respectively in the TPR-A and the IPR-A). Since hedges are usually adopted to refrain the author from making a complete commitment to a proposition (Hyland 1999, 2005, Hu \& Cao 2011), the modals such as should, could, and may were widely used by the students to deliver their conditional epistemological opinions about their practice work in the abstracts. For example:

(3) Certainly, all translators should bear in mind what they seek for is the closest equivalence rather than absolute equivalence. (TPR-A-18)

(4) Professional interpreters should strengthen their capability of cross-cultural interactions. (IPR-A-4)

It can be seen from the two excerpts above that the modal word should is a linguistic device preferred by Chinese students to reach the rhetorical effectiveness of toning down their views. This linguistic option might be influenced by the first language interference when Chinese students express their recommendation or suggestion for future translation/interpretation practice. This was explained in the interview by one supervisor who commented that:

Possibly influenced by the transfer of mother language, Chinese students prefer to use 'ying gai', a Chinese expression that is equivalent to the English modal word 'should', to offer their suggestions. 
In terms of attitude markers, the percentage of attitude markers $(19.4 \%$ in the TPR-A and $9.9 \%$ in the IPR-A) occupied the third place among the four categories of stance. Because one of the communicative purposes of abstracts in the TPR and in the IPR is to report the significance of the translation/ interpretation practice that a student has conducted, some evaluative adjectives such as important or significant were preferred by students to stress the novelty of the translation/interpretation practice task. For instance:

(5) The thesis aims to present the important differences between human translation and machine translation in the context of promising machine translation, and more importantly, to provide constructive suggestions for translators as well as clients and achieve the balance between efficiency and quality. (TPR-A-7)

(6) After interpreting, to summarize and analyze the problems and weaknesses in the on-spot interpreting is particularly important, as it is crucial for seeking coping tactics for emergency and improving flexibility in applying interpreting skills. (IPR-A-15)

This tendency in adopting attitude markers to express one's attitude towards the practice task was further explained by one translation interviewee as follows:

The value of my (translation) practice task can be recognized by the examiners if only its importance is emphasized in the abstract.

As for boosters, they were least adopted in the TPR abstracts (6.5\%) and the IPR abstracts $(6.2 \%)$, which is different from the traditional view that boosters were greatly used in the abstracts of empirical studies to claim the researcher's proposition and to display the research results (Hu \& Cao 2011). Below are two excerpts:

As to this situation, the author believes that MTI students should enhance their academic ability in translation research by strengthening translation practice. (TPR-A-24)

(8) The author also believed that comprehension in the interpretive theory is as important as deverbalization. (IPR-A-19)

As can be seen above, the lowest percentage of the boosters is possibly influenced by a combination of factors. The first factor can be attributed to the generic nature of the non-empirical study of the TPR and the IPR since Hu and Cao (2011) found that the abstracts of the non-empirical academic articles used fewer boosters than those of the empirical academic articles. The second factor is obviously related 
to the culturally-preferred rhetorical strategies. Since boosters indicate writers' certainty about a proposition and confidence in a claim, which is divergent from Chinese Confucius culture of being humble and prudent, Chinese students would unconsciously avoid using boosters to conform with the Chinese rhetorical norms. Besides, the institutional context in the study would also constrain the use of boosters. Since boosters increase the illocutionary force of speech act (Holms 1984), students might use them with caution for the sake of politeness given their role as the examinees. Similarly, as novice learners in the translation and the interpretation field, students would also limit the total commitment into their assertation on the translation and the interpretation findings and to express their open-minded attitudes towards the alternative opinions by using fewer boosters in their abstracts, which help them show their respect to the authoritative knowledge.

\subsection{Variations of stance expression between the TPR abstracts and the IPR abstracts}

Figure 2 shows variations between the TPR abstracts and the IPR abstracts in terms of the frequency and the distribution of the four categories of stance after the raw number of each category was normalized per 1,000 words. It demonstrates both similarities and differences in the use of stance expression between the two subdisciplines in the MTI field.

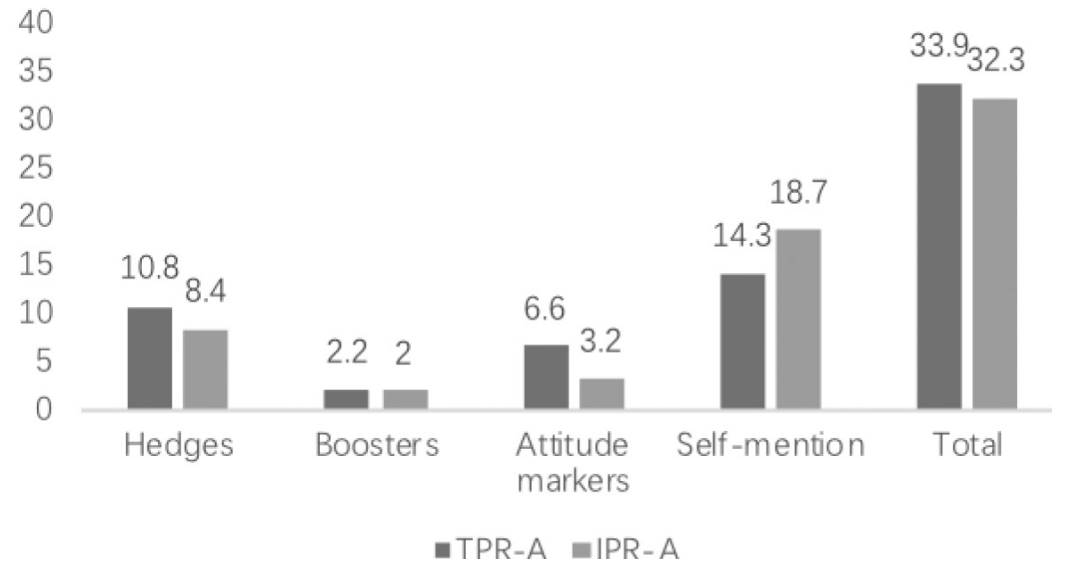

Figure 2: Frequency of each category of stance in the TPR-A and in the IPR-A (per 1,000 words) 
Concerning the similarities, for one thing, the overall use of stance expression displayed a similar frequency in terms of the total number in the two subdisciplines, which was 33.9 per 1,000 words in the TPR-A and 32.3 per 1,000 words in the IPR-A. For another, both the two corpora demonstrated a similar tendency in employing the four categories of stance. Self-mention was the most frequently used stance expression in both of the two subdisciplines, accounting for 14.3 per 1,000 words in the TPR-A and 18.7 in the IPR-A. Hedges were the next frequently used stance expression in both corpora, with the frequency of 10.8 and 8.4 per 1,000 words in the TPR-A and the IPR-A, respectively, then followed by attitude markers, comprising 6.6 per 1,000 words in the TPR and 3.2 in the IPR. Boosters were the least employed stance expression with a frequency of 2.2 and 2 per 1,000 words in the TPR-A and the IPR-A, respectively. Besides, a similarity was also found in students' preference in adopting the specific stance items for each category in the two subdisciplines. For example, self-mention like the author, hedge like can, attitude marker like hope, and booster like believe were commonly employed by both the translation students and the interpretation students. Two excerpts are offered below:

(9) The author hopes that the thesis can become guidance and reference for the translator's further translation study. (TPR-A-10)

(10) The author also hopes that this report can provide some references for those who conduct the work of TCM interpreting in the future. (IPR-A-16)

Those similarities between the two subdisciplines can be firstly attributed to the fact that both the TPR abstracts and the IPR abstracts are written by Chinese students who have the same cultural background. This is in line with the opinion that cultural matters would constrain the writer's academic habits (Hinkel 2002, Uysal 2012). Additionally, since "stance is a community-influenced construct" (Jiang \& Hyland 2015: 530), both the translation students and the interpretation students who are in the same community of the MTI domain in China possibly display a similar tendency in constructing their epistemic stance.

However, some differences still exist in the two subdisciplines. One obvious difference is demonstrated in the different frequencies of the four categories of stance. It can be seen that hedges, boosters, and attitude markers were more frequently used in the TPR-A than in the IPR-A, while self-mention was less frequently employed in the TPR-A (14.3 per 1,000 words) than in the IPR-A (18.7 per 1,000 words). Another distinctive difference is displayed in the use of attitude markers. The frequency of attitude markers in the TPR-A (6.6 per 1,000 words) was a double for that in the IPR-A (3.2 per 1,000 words). Besides, 
an evident discrepancy in students' utilization of specific stance markers for each category was also found between the two subdisciplines. Taking self-mention for example, the translator was exclusively used in the TPR abstracts but the interpreter was entirely employed in the IPR abstracts. A similar phenomenon can also be found in the other three categories of stance. For instance, hedges such as generally and properly only occurred in the TPR abstracts, while tends to, simply and somewhat appeared solely in the IPR abstracts. This discipline-specific utilization of particular stance item is illustrated by the two excerpts below:

If long English sentences can be properly translated, the quality of the translated version will be greatly guaranteed. (TPR-A-20)

(12) The conclusion and suggestions in this paper are somewhat useful for further (interpretation) practices. (IPR-A-1)

Although those differences are not significant, they are mainly caused by the disciplinary conventions in the two subdisciplines. According to Hyland (2005), stance is a "discipline-situated" device. Writers in different disciplines present themselves, deliver epistemic assessments and attitudes in different ways. Hence, the rhetorical practices in constructing stance are constrained by the disciplinary context.

In this study, the TPR abstracts and the IPR abstracts are written by students in the two subdisciplines that focus on two different activities: translation and interpretation. "Translation refers to the rendering of a source-language text into the target-language" (Kettunen 2017: 38), which is a kind of written activity between the texts, while interpretation is the "communicative act of reproducing orally in a target language what a speaker is expressing in a source language" (Riccardi 2002: 75), which is a type of verbal activity between humans. Due to the different natures of the two activities, it generates the varied contexts of the two subdisciplines, which would affect students' rhetorical options in stance making when they write the abstracts. Firstly, as a communication between humans, interpretation involves an evident presence of the interpreter. On the contrary, as a communication between texts, translation allows the translator to be invisible. This might account for the comparatively higher frequency of self-mention in the IPR abstracts than that in the TPR abstracts. Secondly, as a written form, translation work should be formal and have idiomatic lexis. However, interpretation is usually field-specific and is allowed to use non-formal expression. The discrepancy in the lexical requirement might influence students' lexical preference in expressing their stance in the abstracts. Actually, it was found that the translation students preferred to use formal and written vocabulary 
(e.g. significance) in writing the abstracts, while their counterparts did not. This might be attributed to the higher frequencies of hedges, boosters, and attitude markers in the TPR abstracts than those in the IPR abstracts since most items in Hyland's (2005) stance list were generated from the formal academic writing. In the same vein, it can possibly explain why the translation students tended to use the particular stance items such as generally and properly that are usually formal and idiomatic, while the interpretation students preferred to use the stance items such as tends to, simply and somewhat that are colloquial.

\section{Conclusion}

This paper, employing a corpus-based comparative approach, has sought to examine the stance features in the TPR abstracts and the IPR abstracts and to explore the possible variations in the use of stance between the two closely related subdisciplines in the MTI domain in China. In terms of the features of stance expression, the results revealed that both the TPR abstracts and the IPR abstracts seemingly adopted a genre-specific convention in employing the four categories of stance, which is different from that in the genres of empirical studies. Specifically, self-mention was the most frequently adopted stance expression in both the TPR abstracts and the IPR abstracts, followed by hedges, attitude markers, and boosters. It is largely caused by the conventions of the reporting genre that is featured with high self-presence of the writer and the low level of posing propositions in the abstracts.

In terms of variations of stance expression between the TPR abstracts and the IPR abstracts, both similarities and differences existed. Concerning the similarities, the tendency in stance expression in terms of the frequencies of the total number and each category of stance was common in both of the two subdisciplines. With regard to the differences, the four categories of stance, especially the self-mention and the attitude markers, were found to be used in different frequencies between the two corpora. Such differences are mainly caused by disciplinary orientations (Jiang \& Hyland 2015). In addition, those findings were further clarified and confirmed through the information extracted from the interviews, which enriched the sight on how Chinese students expressed their epistemic assessments, attitudes, and presence in the context of the translation and interpretation field.

Regarding implications for expressing stance in the writing of the TPR abstracts and the IPR abstracts, because stance conventions are not always easily understood by foreign language learners due to a lack of explicit attention and practice (Hyland 2012), the findings of this paper suggest that it is necessary to assist students to understand the genre-specific stance conventions and the 
disciplinary variations through a systemic and effective instruction. For example, the corpus data obtained in the current study can be used to help raise students' awareness of stance expression through designing the writing materials with multiple-forms of exercises and through presenting the linguistic resources used for hedges, boosters, attitude markers, and self-mention, which are underdeveloped in the writing of the TPR abstracts and the IPR abstracts by Chinese MTI students. Besides, it can be utilized to expose the students to the preferred stance expression with the explicit instruction and to enhance their discipline-specific learning of stance patterns by offering them with the authentic contexts for some particular stance items in the two different subdisciplines.

However, some unavoidable limitations in this paper are worth mentioning. First, the small number of abstracts collected in the corpus has a limit on the generalization of the stance features obtained in this study. Future studies need to increase the number of abstracts to improve the generalization of the study. Secondly, being prevented by the space, it is a pity that this paper solely reports the results of stance expression in the abstracts section. It is expected that future works can have the opportunity to cover other rhetorical sections to provide a holistic picture of the use of stance in the TPR and the IPR by Chinese MTI students. Doing so would enlighten Chinese MTI students in writing the TPR and the IPR by appropriately employing stance expression to express their personas, epistemic assessment, and attitude, and to construct effective interaction with the examiners and readers. Finally, it could possibly shed light on the utilization of stance expression in other fields.

\section{Appendix A}

The list of stance expression modified from Hyland (2005)

\begin{tabular}{|l|l|l|l|}
\hline Hedges & Boosters & Attitude Markers & Self-mention \\
\hline About & Actually & Admittedly & He \\
A kind of & Always & Agree & I \\
Almost & Believe & Agrees & me \\
Apparent & Believed & Agreed & my \\
Apparently & Believes & Amazed & mine \\
Appear & Beyond doubt & Amazing & our \\
Appeared & Certain & Amazingly & She \\
Appears & Certainly & Appropriate & The author \\
Approximately & Clear & Appropriately & The author's \\
Argue & Clearly & Astonished & The interpreter \\
Argues & Conclusively & Astonishing & The interpreter's \\
Argued & Decidedly & Astonishingly & The reporter \\
Around & Definite & The reporter's \\
Assume & Definitely & Believable & The translator \\
\hline
\end{tabular}




\begin{tabular}{|c|c|c|c|}
\hline Hedges & Boosters & Attitude Markers & Self-mention \\
\hline Assumed & Demonstrate & Correctly & The translator's \\
\hline Attempt & Demonstrated & Crucial & The writer's \\
\hline Broadly & Demonstrates & Curious & We \\
\hline Certain amount & Doubtless & Curiously & \\
\hline Certain degree & Establish & Desirable & \\
\hline Certain extent & Established & Desirably & \\
\hline Certain level & Evident & Disappointed & \\
\hline Claim & Evidently & Disappointing & \\
\hline Claimed & Find & Disappointingly & \\
\hline Claims & Found & Disagree & \\
\hline Can & Finds & Disagrees & \\
\hline Could & Hold & Disagreed & \\
\hline Couldn't & In fact & Dramatic & \\
\hline Doubt & Incontestable & Dramatically & \\
\hline Doubtful & Incontestably & Easily & \\
\hline Essentially & Incontrovertible & Effective & \\
\hline Especially & Incontrovertibly & Essential & \\
\hline Estimate & Indeed & Essentially & \\
\hline Estimated & Indisputable & Even $\mathrm{x}$ & \\
\hline Fairly & Indisputably & Expected & \\
\hline Feel & It is well known & Expectedly & \\
\hline Feels & Know & Fortunate & \\
\hline Felt & known & Fortunately & \\
\hline Frequently & Must (possibility) & Great & \\
\hline From my point of view & Never & Hope & \\
\hline From our perspective & No doubt & Hopeful & \\
\hline From this perspective & Obvious & Hopefully & \\
\hline Generally & Obviously & Important & \\
\hline Generally speaking & Of course & Importantly & \\
\hline Guess & Point out & Inappropriate & \\
\hline Indicate & Prove & Inappropriately & \\
\hline Indicated & Proved & Interesting & \\
\hline Indicates & Proves & Interestingly & \\
\hline In general & Realize & Practical & \\
\hline In most cases & Realized & Prefer & \\
\hline In most instances & Realizes & Preferable & \\
\hline In my opinion & Really & Preferably & \\
\hline In my view & Shall & Preferred & \\
\hline In our opinion & Show & Remarkable & \\
\hline In our view & Showed & Remarkably & \\
\hline Kindly & shows & Shocked & \\
\hline Kind of & Shown & Shocking & \\
\hline Largely & Sure & Shockingly & \\
\hline Likely & Surely & Significant & \\
\hline Mainly & Think & Significance & \\
\hline
\end{tabular}




\begin{tabular}{|c|c|c|c|}
\hline Hedges & Boosters & Attitude Markers & \begin{tabular}{|l|} 
Self-mention \\
\end{tabular} \\
\hline $\begin{array}{l}\text { May } \\
\text { Maybe } \\
\text { Might } \\
\text { Mostly } \\
\text { Often } \\
\text { On the whole } \\
\text { Ought } \\
\text { Particularly } \\
\text { Perhaps } \\
\text { Plausible } \\
\text { Plausibly } \\
\text { Possible } \\
\text { Possibly } \\
\text { Postulate } \\
\text { Postulated } \\
\text { Postulates } \\
\text { Presumable } \\
\text { Presumably } \\
\text { Probable } \\
\text { Probably } \\
\text { Properly } \\
\text { Quite } \\
\text { Rather } \\
\text { Relatively } \\
\text { Roughly } \\
\text { Seems } \\
\text { Should } \\
\text { Simply } \\
\text { Sometimes } \\
\text { Somewhat } \\
\text { Suggest } \\
\text { Suggested } \\
\text { Suggests } \\
\text { Suppose } \\
\text { Supposed } \\
\text { Supposes } \\
\text { Suspect } \\
\text { Suspected } \\
\text { Suspects } \\
\text { Tend to } \\
\text { Tended to } \\
\text { Tends to } \\
\text { To my knowledge } \\
\text { To some extent } \\
\text { To certain extent }\end{array}$ & \begin{tabular}{|l} 
Thinks \\
Thought \\
Truly \\
True \\
Undeniable \\
Undeniably \\
Undisputedly \\
Undoubtedly \\
Will \\
Without doubt
\end{tabular} & \begin{tabular}{|l} 
Striking \\
Strikingly \\
Skillfully \\
Surprised \\
Surprising \\
Surprisingly \\
Unbelievable \\
Unbelievably \\
Understandable \\
Understandably \\
Unexpected \\
Unexpectedly \\
Unfortunate \\
Unfortunately \\
Unusual \\
Unusually \\
Usual
\end{tabular} & \\
\hline
\end{tabular}




\begin{tabular}{|l|l|l|l|}
\hline Hedges & Boosters & Attitude Markers & Self-mention \\
\hline Typical & & & \\
Typically & & & \\
Uncertain & & & \\
Uncertainly & & & \\
Unclear & & & \\
Unclearly & & & \\
Unlikely & & & \\
Usually & & & \\
Would & & & \\
Would not & & \\
\hline
\end{tabular}

Note: The stance expressions in bold are discipline-specific in the TPR or the IPR, which are added by the researchers.

\section{Appendix B}

\section{Interview on Stance Expression in the Abstracts of the TPR and the IPR}

Purpose: The interview aims to collect information on stance expression in the writing of the TPR abstracts and the IPR abstracts from the insider informants.

Format: A semi-structured format

Interviewer: One of the researchers

Interviewees: 2 supervisors (a male professor who has been MTI supervisor for 5 years and has instructed the MTI Theses Writing for 2 years, apart from his 25 years of English teaching for Chinese students; a female Associate Professor who has been MTI supervisor for 2 years and has about 20 years English teaching experience).

4 students ( 2 translation students, 1 male and 1 female; 2 interpretation students, 1 male and 1 female. All of them have already completed the writing of their theses.)

The supervisors and student interviewees were sampled purposefully from the university in the south of China where one of the researchers is working.

Ways of Interview: Online interview via Wechat

Time: The supervisors' interview and the students' interview will be conducted separately. It is about 30 minutes for each.

\section{Language: Chinese}

Confidentiality: This interview is used only for research purpose, which will not harm your own privacy. There is no right and wrong answer. Please answer questions according to your own understanding.

\section{Warming-up Question:}

Can you generally talk about the use of stance expression (i.e. hedges, boosters, attitude markers, and self-mentions) in the TPR abstracts and in the IPR abstracts? 


\section{Interview Questions:}

1. Have students in the MTI field received any instructions on the language use that facilitates the stance expression in abstracts? If yes, can you say something about them?

2. According to your writing/teaching experiences, which category of stance do students use most (least) in writing their abstracts? Can you explain the reasons for the tendency of stance expression from the perspective of the generic nature of the TPR/IPR abstracts?

3. Do you think the stance expression can be affected by students' background, such as their social-cultural background, institutional context, linguistic proficiency, translation/interpretation practice, personal writing experience, and so on? If yes, can you say something about them?

4. Do you think there are differences in the use of stance between the abstracts of TPR/IPR and the abstracts of other genres (e.g. M.A theses)? If any, can you say something about them?

5. Are there any differences related to the writing conventions and practices between the translation subdiscipline and the interpretation subdiscipline? If yes, would those differences influence the stance expression in abstracts writing? Can you explain them with some examples?

\section{Acknowledgements}

We would like to thank the editors and the anonymous reviewers for their valuable comments on the previous versions of the manuscript. We would also like to acknowledge the financial support by Suranaree University of Technology, Thailand.

\section{References}

Adams, H. and Quintana-Toledo, E. (2013) 'Adverbial stance marking in the introduction and conclusion sections of legal research articles.' Revista de Lingüisticay Lenguas Aplicadas 8(1), 13-22.

Ahmad, U. and Mehrjooseresht, M. (2012) 'Stance adverbials in engineering thesis abstracts.' Procedia-Social and Behavioral Sciences 66, 29-36.

Anthony, L. (2011) Antconc (Version 3.2.4). Tokyo, Japan: Laurence Anthony, University of Waseda.

Aull, L. L., Bandarage, D. and Miller, M. R. (2017) 'Generality in student and expert epistemic stance: A corpus analysis of first-year, upper-level, and published academic writing.' Journal of English for Academic Purposes 26, 29-41.

Aull, L. L. and Lancaster, Z. (2014) 'Linguistic markers of stance in early and advanced academic writing: A corpus-based comparison.' Written Communication 31(2), 151-183. 
Auría, M. C. P. L. (2008) 'Stance and academic promotionalism: A cross-disciplinary comparison in the soft sciences.' Journal of the Spanish Association of AngloAmerican Studies 30(1), 129-145.

Biber, D. (2006) 'Stance in spoken and written university registers.' Journal of English for Academic Purposes 5(2), 97-116.

Biber, D., Connor, U. and Upton, T. A. (2007) Discourse on the Move: Using Corpus Analysis to Describe Discourse Structure. Amsterdam: John Benjamins.

Bowden, J. (2004). Writing a Report: How to Prepare, Write, and Present Effective Reports. Londonderry: Spring Hill House.

Çandarli, D., Bayyurt, Y. and Marti, L. (2015) 'Authorial presence in L1 and L2 novice academic writing: Cross-linguistic and cross-cultural perspectives.' Journal of English for Academic Purposes 20, 192-202.

Chafe, W. L. and Nichols, J. (eds) (1986) Evidentiality: The Linguistic Coding of Epistemology. New Jersey: Ablex Publishing Corporation.

Chan, T. H. T. (2015) 'A corpus-based study of the expression of stance in dissertation acknowledgements.' Journal of English for Academic Purposes 20, 176-191.

Cheng, F. W. and Unsworth, L. (2016) 'Stance-taking as negotiating academic conflict in applied linguistics research article discussion sections.' Journal of English for Academic Purposes 24, 43-57.

Crosthwaite, P., Cheung, L. and Jiang, F. K. (2017) 'Writing with attitude: Stance expression in learner and professional dentistry research reports.' English for Specific Purposes 46, 107-123.

Fuoli, M. (2017) 'Building a trustworthy corporate identity: A corpus-based analysis of stance in annual and corporate social responsibility reports.' Applied Linguistics 39(6), 846-885.

Gillaerts, P. and Van de Velde, F. (2010) 'Interactional metadiscourse in research article abstracts.' Journal of English for Academic Purposes 9(2), 128-139.

Hinkel, E. (2002) Second Language Writers' Text: Linguistic and Rhetorical Features. Mahwah, New Jersey: Lawrence Erlbaum Associates.

Holmes, J. (1984) 'Modifying illocutionary force.' Journal of Pragmatics 8, 345-365.

$\mathrm{Hu}, \mathrm{G}$. and Cao, F. (2011) 'Hedging and boosting in abstracts of applied linguistics articles: A comparative study of English- and Chinese-medium journals.' Journal of Pragmatics 43(11), 2795-2809.

Huang, G. W. (2012) A Guide to Writing MTI Dissertations. Beijing, China: Foreign Language Teaching and Research Press.

Hyland, K. (1999) 'Disciplinary discourses: Writer stance in research articles.' In: Candlin, C. N. and Hyland, K. (eds) Writing: Texts, Processes and Practices. London: Longman. 99-121.

Hyland, K. (2000) Disciplinary Discourses: Social Interactions in Academic Writing. London: Longman.

Hyland, K. (2005) 'Stance and engagement: A model of interaction in academic discourse.' Discourse Studies 7(2), 173-192.

Hyland, K. (2012) Disciplinary Identities: Individuality and Community in Academic Discourse. Cambridge: Cambridge University Press.

Hyland, K. (2017) 'Metadiscourse: What is it and where is it going?' Journal of Pragmatics $113,16-29$.

Hyland, K. and Jiang, F. (2016) 'Change of attitude? A diachronic study of stance.' Written Communication, 33(3), 251-274. 
Hyland, K. and Tse, P. (2004) 'Metadiscourse in academic writing: A reappraisal.' Applied Linguistics 25(2), 156-177.

Hyland, K. and Tse, P. (2005) 'Hooking the reader: A corpus study of evaluative that in abstracts.' English for Specific Purposes 24(2), 123-139.

Jiang, F. (2015) 'Noun stance in argumentative essays by Chinese and American student: A corpus-based contrastive investigation (zhongmei xuesheng lunshuowen de lichang minci biaoda).' The Journal of Foreign Language and Foreign Language Teaching 5, 8-14.

Jiang, F. and Hyland, K. (2015) 'The fact that: Stance nouns in disciplinary writing.' Discourse Studies 17(5), 529-550.

Kafes, H. (2018) 'Stance in academic writing.' European Journal of Education Studies 4(2), 1-15.

Kettunen, J. (2017) 'Interlingual translation of the International Financial Reporting Standards as institutional work.' Accounting, Organizations and Society 56, 38-54.

Lancaster, Z. (2016) 'Expressing stance in undergraduate writing: Discipline-specific and general qualities.' Journal of English for Academic Purposes 23, 16-30.

Loi, C. K., Lim, J. M. H. and Wharton, S. (2016) 'Expressing an evaluative stance in English and Malay research article conclusions: International publications versus local publications.' Journal of English for Academic Purposes 21, 1-16.

Martin, J. R. and White, P. R. (2005) The Language of Evaluation: Appraisal in English. New York: Palgrave Macmillan.

McGrath, L. and Kuteeva, M. (2012) 'Stance and engagement in pure mathematics research articles: Linking discourse features to disciplinary practices.' English for Specific Purposes 31(3), 161-173.

Poole, R., Gnann, A. and Hahn-Powell, G. (2019) 'Epistemic stance and the construction of knowledge in science writing: A diachronic corpus study.' Journal of English for Academic Purposes 42, 1-11.

Riccardi, A. and Alessandra, R. (2002) Translation Studies: Perspectives on an Emerging Discipline. Cambridge: Cambridge University Press.

Swales, J. (1990) Genre analysis: English in Academic and Research Settings. Cambridge: Cambridge University Press.

Taki, S. and Jafarpour, F. (2012) 'Engagement and stance in academic writing: A study of English and Persian research articles.' Mediterranean Journal of Social Sciences 3(1), 157-168.

Thompson, G. and Hunston, S. (2000) 'Evaluation: An introduction.' In: Hunston, S. and Thompson, G. (eds) Evaluation in Text: Authorial Stance and the Construction of Discourse. Oxford: Oxford University Press. 1-27.

Uysal, H. H. (2012) 'Argumentation across L1 and L2 writing: Exploring cultural influences and transfer issues.' Vial, Vigo International Journal of Applied Linguistics 9, 133-156.

Vande Kopple, W. (1985) 'Some exploratory discourse on metadiscourse.' College Composition and Communication 36, 82-93.

$\mathrm{Xu}, \mathrm{F}$. (2015) 'Investigation on authorial stance in academic writing by L2 writers (eryu xueshu yupian zhong de zuozhe lichang biaoji yanjiu).' Journal of Foreign Language and Teaching 284(5), 1-7. 
Fengling Wang is Lecturer at the Faculty of Foreign Languages and Cultures, Kunming University of Science and Technology, China. She is currently a Ph.D. student in the School of Foreign Languages, Suranaree University of Technology, Thailand. Her research interests include discourse and genre analysis, as well as the writing of ESP learners.

Address: Fengling Wang, Faculty of Foreign Languages and Cultures, Kunming University of Science and Technology, Jingming South Road No.727, Chenggong District, Kunming, Yunnan, 650500. [e-mail: wflzf11@126.com]

Issra Pramoolsook is Assistant Professor in Applied Linguistics and ELT at Suranaree University of Technology, Thailand. His research interests include discourse and genre analysis, disciplinary and professional discourses, and academic and professional writing, especially with genre-based approach. He is the corresponding author of the present paper.

Address: Issra Pramoolsook, School of Foreign Languages, Institute of Social Technology, Suranaree University of Technology, Muang, Nakhon Ratchasima, Thailand 30000. [e-mail: issra@sut.ac.th] 